\title{
Modelling glaciers' melting in Central Caucasus (the Djankuat and Bashkara Glacier case study)
}

\author{
Egor Belozerov ${ }^{1 *}$, Ekaterina Rets ${ }^{1}$, Dmitry Petrakov ${ }^{2}$, and Viktor Popovnin ${ }^{2}$ \\ ${ }^{1}$ Water Problems Institute, Russian Academy of Sciences, 3 Gubkina, 119333, Moscow, Russia \\ ${ }^{2}$ Lomonosov Moscow State University, Leninskie Gory, Moscow, 119991, Russia
}

\begin{abstract}
The A-melt model was applied to assess the contribution snow and ice melting to river flow during the summer period of 2017 for the Bashkara and Djankuat glaciers located in the Caucasus. During the study period, the Djankuat river runoff amounted to 120 thousand $\mathrm{m}^{3}$, while the peak value of snow and ice melting was 300-400 thousand $\mathrm{m}^{3}$ per day, and on average 189 thousand $\mathrm{m}^{3}$. The significant influence of groundwater on the river flow is traced. The melt water contribution to the glacial lake Bashkara outburst manifested in the gradual accumulation of water large volumes over the summer period. The melting of snow and ice the day before the lake outburst reached 31 thousand $\mathrm{m}^{3}$, with an average value of 192 thousand $\mathrm{m}^{3}$ for the Bashkara basin. The total melting volume of the Djankuat basin was $0.016 \mathrm{~km}^{3}$, and of the Bashkara basin $-0.017 \mathrm{~km}^{3}$. As a result, the A-Melt model demonstrates the evaluation ability of glaciers' impact on mountain rivers runoff.
\end{abstract}

\section{Introduction}

Fresh water shortage is one of the global problems of our time. Glaciers are one of the main components of freshwater supplies on our planet. Nowadays general degradation of mountain glaciation in the world is observed [1-3], which leads, on the one hand, to an increase of rivers runoff at the alpine zone, and on the other hand, to a decrease of age-old storages of fresh water in glaciers [4]. This problem is especially relevant for the mountainous and arid regions of our planet. The example of glacial fresh water supplies exhaustion in the Central Caucasus is the representative glacier Djankuat, where since 1974 the volume of the glacier has almost halved, by 2013 it was about $0.077 \pm 0.002 \mathrm{~km}^{3}$ [5]. In total, the glaciers of Caucasus area have decreased by $4.7 \pm 2.1 \%$ or $19.2 \pm 8.7 \mathrm{~km}^{2}$ from $407.3 \pm 5.4 \mathrm{~km}^{2}$ to $388.1 \pm 5.2 \mathrm{~km}^{2}$ since 1987 to 2010 [6]. From 2006 to 2015 the volume of the Djankuat glacier decreased by $25 \%$ which shows an increase in the rates of glacier degradation [5].To assess the melting of glaciers and their contribution to the glacial runoff, the mathematical simulation method was used. This method is quite common and widely used in many mountainous areas of the Earth [4,7-10].

For the Caucasus region, two neighboring glaciers of Djankuat and Bashkara, which are typical valley glaciers, were selected as the objects of the study. This choice is due to the fact that the Djankuat glacier was the object of mass-balance observations since 1965, as it

${ }^{*}$ Corresponding author: egora1000@mail.ru 
was chosen as representative of the central North Caucasus during the International Hydrological Decade (IHD) - research program on water problems launched by UNESCO in 1965 [11]. The Bashkara glacier has two adjacent glacial lakes, where in 2017 there was a mudflow along the Adyl-Su river valley [12]. To study the contribution of glacial runoff to this phenomenon, the processes of snow and ice melting were simulated. The Djankuat glacier has already been the object of modelling in several studies [13-14].

\section{Study area}

The Central Caucasus is the highest and most inaccessible part of the Greater Caucasus. Its borders run along the Elbrus in the west and Kazbek in the east, the average width of the mountain system varies from 180 to $110 \mathrm{~km}$. The general direction of the mountain massif here is from the north-west to the south-east. The length of the Greater Caucasus on this section is $190 \mathrm{~km}$, the average height is about $3400-3500 \mathrm{~m}$.

The mountain glacial basins of Djankuat and Bashkara are located in the drive-divide part of the northern slope of the Greater Caucasus Range, in the upper part of the river valley Adyl-Su, the right tributary of the Baksan River. The total area of the Djankuat basin is $8.05 \mathrm{~km}^{2}$, the average height of the glaciers in the basin is about $3250 \mathrm{~m}$, and the surface not covered by glaciers begins from $3200 \mathrm{~m}$ to sea level. The watershed line in the relief is clearly expressed and partially runs along the Greater Caucasus ridge at an altitude of 3600$4000 \mathrm{~m}$. On the left, the border runs along the spur of Mount Dzhantugan, on the right along the spur of Kurmychi. The lower boundary of the basin is located at an altitude of $2680 \mathrm{~m}$, so the basin is located in the altitude range of 2680-4000 $\mathrm{m}$ [15]. The Bashkara Glacier is located on the territory of the lake Lapa basin which has an area of $9.05 \mathrm{~km}^{2}$. The weighted average basin height is $3350 \mathrm{~m}$, where the highest point of watershed also runs along the Main Range. The lower boundary of the basin is at an altitude of $2520 \mathrm{~m}$.

There are 4 glaciers in the Djankuat river basin: the Djankuat, Koyavgan, Viatau and Visyachii glaciers. The Djankuat glacier is a typical plain valley glacier. According to 2007 data, the Djankuat glacier area was $2.930 \mathrm{~km}^{2}$; in 2013 , the glacier area has dropped to $2.488 \mathrm{~km}^{2}$ [5]. The volume of the glacier for 2013 was $0.077 \mathrm{~km}^{3}$ [16]. The thickness of the ice of the glacier reaches $100 \mathrm{~m}$. The tongue of glacier descends into the valley to a height of $2710 \mathrm{~m}$.

In the same valley the glacial lake Bashkara was formed by the eponymous glacier. The Bashkara glacier has a length of $4 \mathrm{~km}$ and an area of about $3.84 \mathrm{~km}^{2}$, it is located in the upper part of the Adyl-Su basin and it is a valley glacier [17]. The first outbursts of Lake Bashkara were recorded in 1958, 1959 and 1960. By 2005, the area of Lake Bashkara was 66.8 thousand $\mathrm{m}^{2}$, and the volume was about 800 thousand $\mathrm{m}^{3}$, the depth of the lake reached more than 30 meters. By 2016, the volume of the lake increased to 1,000 thousand $\mathrm{m}^{3}$. On September 1, 2017, the mudflow occurred in the Adyl-Su river valley [12]. As a result, the volume of water decreased by 800 thousand $\mathrm{m}^{3}$. The reason for this event is the abnormal amount of precipitation $-134 \mathrm{~mm}$ in two days.

\section{Methods and results}

The A-Melt model is based on the heat balance equation (1). Snow and ice melt under the influence of thermal energy coming to the surface of snow or ice. The heat balance of the surface of snow or ice is defined as [13]:

$$
\omega=\left(S_{b}+S_{d f}\right)(1-A)+E_{a}-E_{z} \pm \omega_{t} \pm Q_{m} \pm Q_{t},
$$


where $\mathrm{S}_{\mathrm{b}}$ - incoming direct short-wave radiation; $\mathrm{S}_{\mathrm{df}}$ - diffused short-wave radiation; $\mathrm{A}$ surface albedo; $\mathrm{E}_{\mathrm{a}}$ - long-wave counter radiation of the atmosphere; $\mathrm{E}_{\mathrm{z}}$ - long-wave radiation of the Earth's surface; $\omega_{\mathrm{t}}$ - turbulent sensible and latent heat fluxes; $\mathrm{Q}_{\mathrm{m}}$ - heat flow through the debris cover; $\mathrm{Q}_{\mathrm{t}}$ - energy change due to snowpack processes.

The input data includes the following characteristics measured with an hourly or other time step: 1) $\mathrm{Sg}$ - total short-wave radiation at a horizontal site, $\mathrm{W} / \mathrm{m}^{2}$; 2) $\mathrm{E}_{\mathrm{a}}$ - long-wave counter radiation of the atmosphere, $\left.\mathrm{W} / \mathrm{m}^{2} ; 3\right) \mathrm{T}(\mathrm{H})$ - air temperature at different elevation in the basin, ${ }^{\circ} \mathrm{C}$; 4) $\mathrm{U}$ - wind speed, $\mathrm{m} / \mathrm{s}$; 5) relative humidity, \%; 6) precipitation amount, $\mathrm{mm}$. For modelling the file with the characteristics of the watershed surface over a regular net, including elevation, snow cover melting off dates, firn line, debris extend and thickness distribution, glacier outlines was prepared by using the ArcGIS program. The meteorological data as well as the Djankuat river hydrograph for the modelling period were obtained from the open-access database [18].

The results of the Djankuat river hydrograph separation into liquid precipitation and melt runoff components after [19] were used in the study. The material of the current state of glaciation, orography, topography and climate has been collected and described. The current trends of glacial runoff were assessed. The glaciation regime was analyzed relying on the materials of observations at the Djankuat research station since 1965.

To achieve the objectives, various research methods were used: calculation of the balance components of glaciers using mathematical simulation; calibration of the A-melt melting model using glaciological ablation observation data; decoding satellite images; spatial-temporal assessment of the minimum, average and maximum water discharge in the study area using the analysis of differential-integral curves; measurement of water discharge at the hydrological gauge "Djankuat"; recovery of missing data by building empirical dependencies.

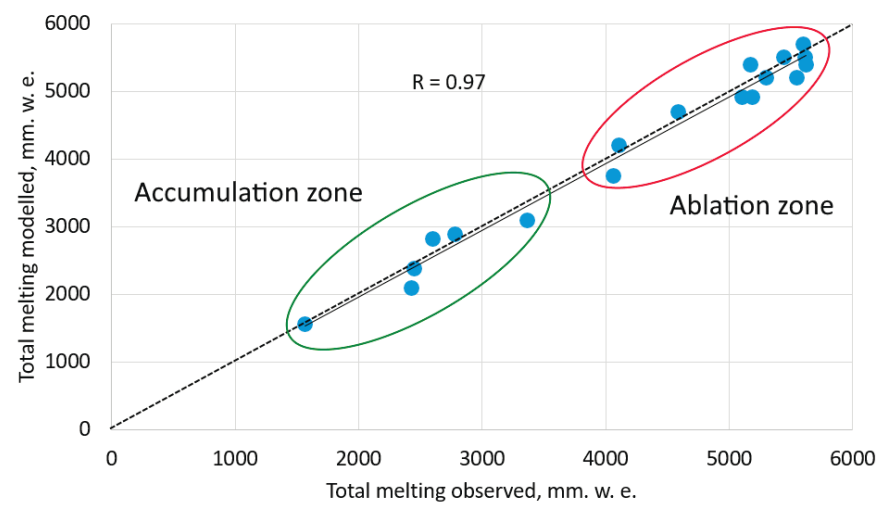

Fig. 1. Verification of the A-Melt model for the Djankuat glacier.

Modeling of the Djankuat and Bashkara glaciers melting was carried out for the period from the $13^{\text {th }}$ of June to the $7^{\text {th }}$ of September 2017. The choice of this period is associated with the lack of meteorological data, including for winter time. The modelling results were verified using the data on the Djankuat glacier ablation, the measurements were performed on the ablation stakes net [17]. Using regular observations, the model was calibrated by comparison of actual data (measured glacier mass balance using ablative rails, snowmeasuring data at the beginning of the summer period), and the model results (Fig. 1.). As a result, such parameters as albedo and temperature gradient were estimated. After verification of the model, the temperature gradient was assessed as $9.5^{\circ} \mathrm{C}$ by $1 \mathrm{~km}$ of height. In the accumulation zone, correlation coefficient between the observed and modelled values is 0.93 , and in the ablation zone, 0.94 . 
The highest value of melting during the summer period, about 4500-5500 millimeters of water equivalent ( $\mathrm{mm}$ w.e), is observed in the ablation zone of the Djankuat glacier. The average total melting of the Djankuat glacier during summer period was estimated as 2788 mm w.e. (Fig. 2a). The total volume of melting amounted to $0.016 \mathrm{~km}^{3}$.

For the Bashkara glacier, the calculations were also performed using the A-melt model. Two zones are observed here with minimum melting rates. The first is the accumulation zone, where snow lies all year round. The second is a zone with a debris cover thickness of more than $30 \mathrm{~cm}$. Here the average total melting was estimated as $200-500 \mathrm{~mm}$ w.e. The maximum values of $3500-4500 \mathrm{~mm}$ w.e. were estimated for the axial parts of the glacier with characteristic maximum ice flow rates. By June 13 2017, snow had already melted off in the lower part of the Bashkara lakes catchment area. As a result, for the most elevated parts, total melting of snow and ice reaches values of 500-1500 mm w.e. The average total melting for the Bashkara glacier during summer period is $2525 \mathrm{~mm}$ w.e. (Fig $2 \mathrm{~b}$ ). The total melting volume is $0.017 \mathrm{~km}^{3}$.

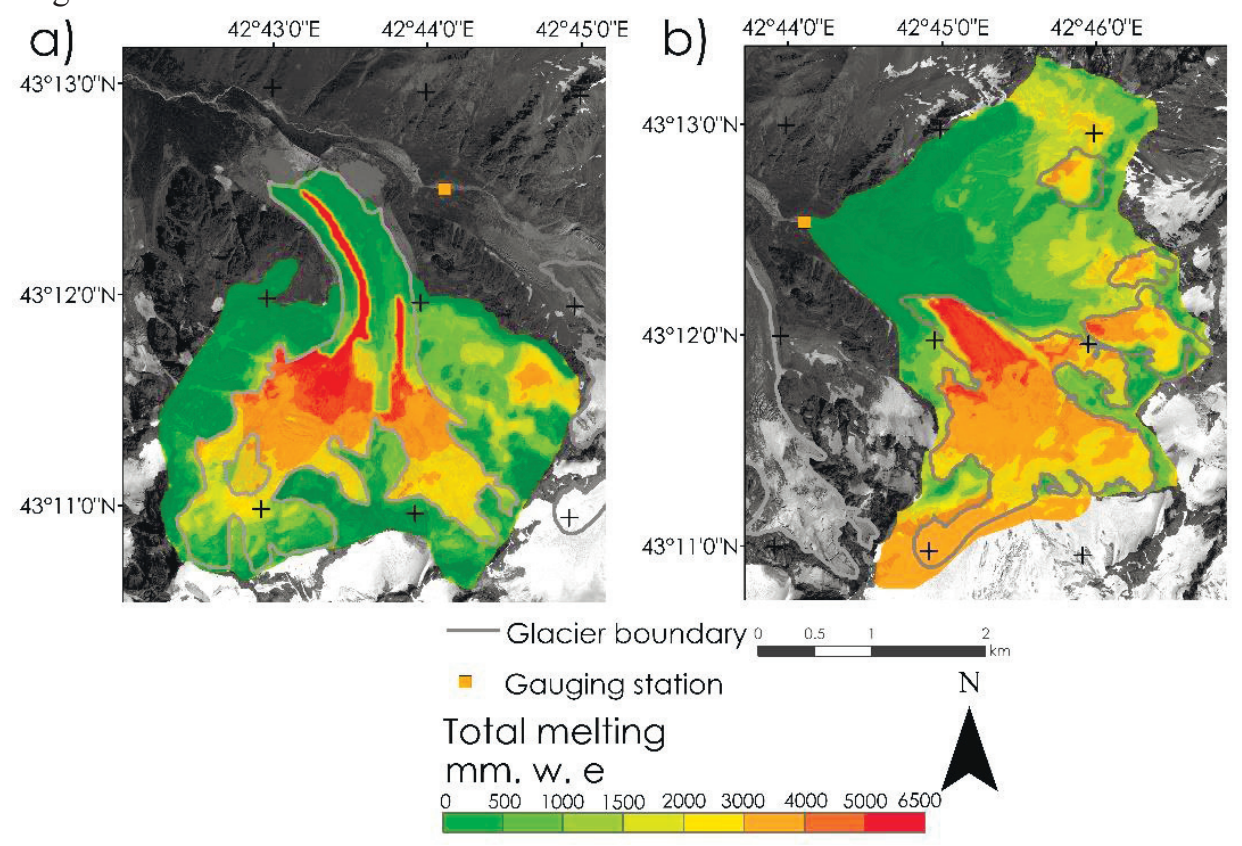

Fig. 2. The total melting of snow and ice for the Djankuat hydrological basin (a) and glacier Bashkara (b) in $\mathrm{mm}$ w. e. according to the A-melt model (gray bar - glacier boundary, orange square -Djankuat hydrological gauge).

The comparison of Djankuat glacier melting dynamics and Djankuat river runoff shows that water discharge and glacier melting do not always correlate closely with each other, due to the effect of the delay in melt water routing (Fig. 2). The time lag between the end of melting and the reaction of the Djankuat river hydrograph varies from 2 days in June to 1 day in July-August (Fig. 3a). The same or a bit shorter time lag is characteristic for liquid precipitation events (Fig.3b). The larger time lag in June can be associated with a wide spread of seasonal snow cover in the basin and the delayed meltwater and rainwater routing through snowpack. There is a significant influence of precipitation on melt runoff. The extreme event, when during 5 days, from 28 August to 1 September, the Djankuat and Bashkara basins received almost $200 \mathrm{~mm}$ of liquid precipitation led to a 2-fold increase in water runoff in the Djankuat River, from 60 to 120 thousand $\mathrm{m}^{3}$ per day (Fig. 2b). According to isotopic the hydrograph separation results, the resulting rise in runoff was by $50 \%$ generated by the meltwater mobilized by the intensive rain flood from the subsurface 
water horizons (Fig. 2b). The average value of melt runoff over the entire period was 45 thousand $\mathrm{m}^{3}$, with a gradual increase towards the end of July and after a rather sharp decrease. In September, melt runoff was 9 thousand $\mathrm{m}^{3}$. In the last 7 days before the outburst of the Lake Bashkara 1 September 2017 melt runoff sharply decreased from 40 thousand $\mathrm{m}^{3}$ to 5 thousand $\mathrm{m}^{3}$ due to decrease in solar radiation amount and air temperature under cyclonic weather conditions. However, over the entire summer period, large volumes of melted snow and ice affected this event in the form of accumulated water in the Lake Bashkara (Fig. 2b).

At the time of the outburst of the Lake Bashkara, the total amount of melting of the Bashkara glacier for 15 days from 28 August to 31 August reached 158 thousand $\mathrm{m}^{3}$. At the same time, on 31 August the total amount of melting was only 47 thousand $\mathrm{m}^{3}$, with an average value of 192 thousand $\mathrm{m}^{3}$ per day for the study period. The contribution of glacial runoff in this period was minimal. The final difference between Djankuat and Bashkara basins is an inessential excess $\left(0.001 \mathrm{~km}^{3}\right)$ of melting water volume incoming to the river network of Bashkara, mainly due to the larger area of the Bashkara glacier more on 1.43 $\mathrm{km}^{2}$.
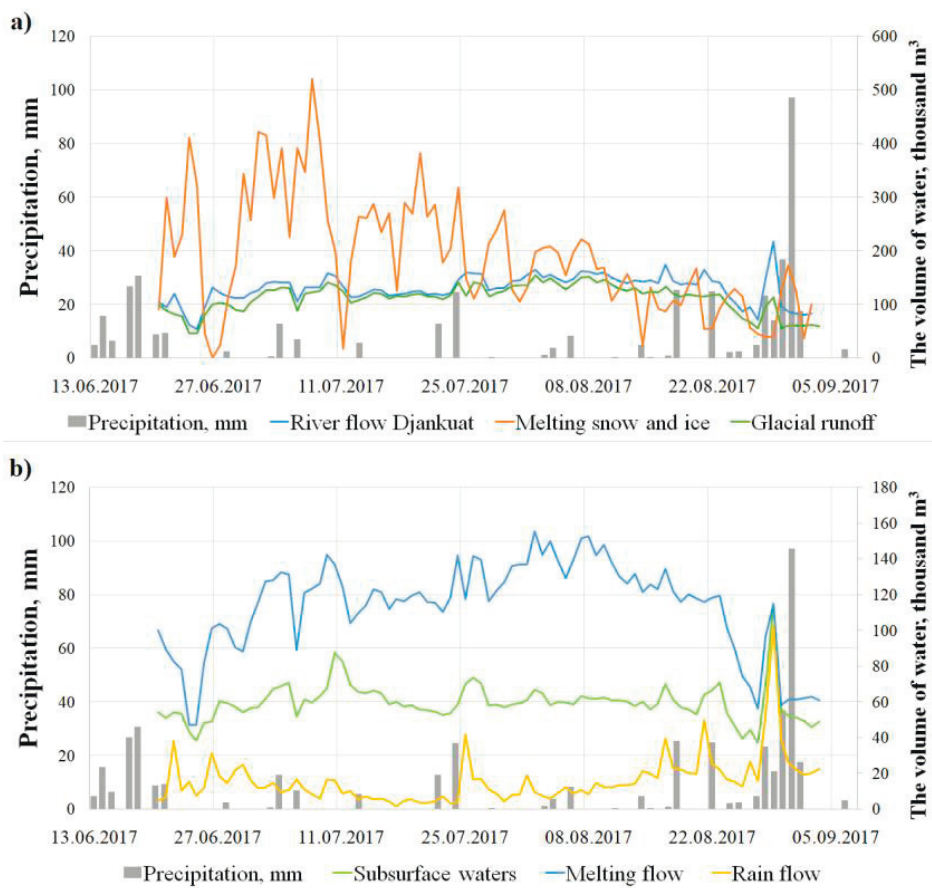

Fig. 3. Observation data at the Djankuat hydrological gauge: (a) flow volume of the Djankuat river (blue line), total volumes of melting snow and ice for the Djankuat glacier (orange line), precipitation (gray columns) and glacial runoff (green line); (b) melt runoff of the Djankuat River (blue line), subsurface feeding of the Djankuat River (green line), rain flow (green line) and precipitation (gray columns).

\section{Conclusion}

The processes of snow and ice melt at the Bashkara and Djankuat glaciers were simulated from 13 June to 7 September, 2017 in the context of glacial runoff assessment task. The average total melting for the Djankuat glacier was $2788 \mathrm{~mm}$ w.e. For the glaciers in the Djankuat river basin, the total melting volume was estimated as $0.016 \mathrm{~km}^{3}$. The runoff of 
the Djankuat river on average during the study period was 120 thousand $\mathrm{m}^{3}$ per day, while in June the volumes of melting snow and ice reach 300-400 thousand $\mathrm{m}^{3}$, which is almost 3 times more than the river runoff. The average value of the total volume of melting is 189 thousand $\mathrm{m}^{3}$ per day, which is by $33 \%$ more than the river runoff volume. The maximum values of melt runoff are observed in late June - early July. The comparison of the Djankuat glacier melting dynamics and Djankuat river runoff shows that river flow and melt water from the glacier do not always correlate closely with each other, due to the effect of the delay in melt water routing.

For the Bashkara glacier, the average total melting was $2525 \mathrm{~mm}$ w.e. The total melting volume was estimated as $0.017 \mathrm{~km}^{3}$. By the time of the outburst of the Bashkara lake, the total volume of melting of the Bashkara glacier for 15 days from August 28 to August 31 amounted to 158 thousand $\mathrm{m}^{3}$. At the same time, on August $31-$ only 47 thousand $\mathrm{m}^{3}$, with an average value of 192 thousand $\mathrm{m}^{3}$ per day for the study period. The contribution of glacial runoff these days was minimal. However, over the entire summer period, large volumes of melted snow and ice affected this event in the form of accumulated water in the Bashkara lake.

This work is supported by the grant of the president of the Russian Federation for young scientists MK-2936.2019.5. in the part of modelling and by the Russian Foundation for Basic Research (grant no. 18-05-00420) in part of processing of the glaciological observations.

\section{References}

1. R. Fausto, D. vanAs, J Box, W. Colgan, L. Langen, H. Mottram., Geophys. Res. Lett., 43, 2649-2658 (2016)

2. V. Panov, St. Petersburg: Gidrometeoizdat, 432-436(1993)

3. D. Duethmann, C. Menz, T. Jiang, S. Vorogushyn. Environ. Res. Lett., 11, 5, 054024 (2016)

4. Sorg, T. Bolch, Nat. Clim. Chan. 2 (10): 725 - 731(2012)

5. Lavrentiev, S. Kutuzov, D. Petrakov, G. Popov, V. Popovnin. Ice and Snow., 4, 7-19, (2014)

6. M. Shahgedanova, G. Nosenko, S. Kutuzov, O. Rototaeva, T. Khromova, Cryosphere, 8, 2367-2379, (2014)

7. V. Tangborn, Geogr. Ann., 66A(3), 257-265, (1984)

8. F. Pellicciotti. PhD thesis, ETHZ Zurich. (2004)

9. Kemmerikh, Data Glaciol. Stud. 20, 82-94, (1972)

10. R Hock, 29-3, 362-391, (2005)

11. V. Popovnin, D. Petrakov. MGI, 98, $167-174,(2005)$

12. S. Chernomorets, D. Petrakov, A. Aleinikov, M. Bekkiev, K. Viskhadzhieva, M. Dokukin, R. Kalov, V. Kidyaeva, V. Krylenko, I. Krylenko, E. Retz, E. Savernyuk, A. Smirnov., Cryosphere of the Earth., 22-2, 70-80 (2018)

13. E. Rets, N. Frolova, V. Popovnin, 2011 Ice and Snow, 4, 116-124, (2011)

14. O. Rybak, E. Rybak,Earth and Env. Sci., 107, 1-6, (2018)

15. L. Golubev, M. Dyurgerov, V. Markin, L. Berry, L. Sukhanov, E. Zolotarev, A. Danilina, Y. Arutyunov., Gidrometeoizdat, 184 (1978)

16. S. Kutuzov, I. Lavrentyev, E. Vasilenko, Y. Macheret, D. Petrakov, G. Popov,Cryosphere of the Earth, 19-1, 78-88. (2015)

17. Krylenko, D. Petrakov, S. Chernomorets, O. Tutubalina, M. Shahmina, I. Krylenko, C. Noreen. Int. Cent. Asian Conf. Remote sens. of the Earth and geoinf. Syst. 1-3, (2008)

18. E. Rets, V. Popovnin, P. Toropov, ESSD, 11-3, 1463-1481, (2019)

19. E. Rets, J. Chizhova, N. Loshakova, I. Tokarev, M. Kireeva, N. Budantseva, Y. Vasil'chuk, N. Frolova, V. Popovnin, P. Toropov, E. Terskaya, A. Smirnov, E. Belozerov, M. Karashova. Front. Earth Sci., 11, 531-543, (2017) 